\title{
Research and Analysis about System of Digital Agriculture Based on a Network Platform
}

\author{
Duan Yane \\ School of Computer \& Information Engineering, Beijing Agricultural College, \\ Beijing, P. R. China
}

\begin{abstract}
Digital Agriculture is an "intelligent" computer management and application system that includes many high technologies of, such as infomationization, digitization, network, automation and more so on. On the basis of analyzing the main content and meaning of "Digital Agriculture", this paper designs the system construction of "Digital Agriculture" based on Internet, and discusses the function and structure of main core modules of System of Digital Agriculture in detail. Finally, this paper also analyzes the developing trend about system of "Digital Agriculture".
\end{abstract}

Keywords: Digital Agriculture, Decision Support System of Agriculture, Agriculture Module.

\section{Preface}

The former American vice-president AI Gore put forward the concept of introduced the term "Digital Earth" in a speech addressed at the California Science Center on January 31, 1998. From that time, the concept of "Digital Earth" has aroused great concern and become one of the newest researching hotspots in global science and technology field. It has remarkably accelerated the development of digitalization in different fields. Digital Agriculture is one of the most important parts of Digital Earth and is the extending of "Information Superhighway", "Digital Earth" and "Knowledge Economy" within the field of agriculture. Digital Agriculture is a comprehensive technology system of agricultural production and management combined the technology of Digital Earth with the technology of modern agriculture. It is the only way of the future in agriculture modernization, integration, and automation and can advance agriculture technology revolution. It brings about the further developing trend of agriculture in Digital Agriculture bring agriculture into the informational generation.

\section{Introduction of "Digital Agriculture"}

In the new century, agriculture will turn into water-saving agriculture, mechanical and intelligent agriculture, and high-quality, high-yield, pollution-free agriculture. Digital Agriculture is a necessary and effective approach to realize all of these purposes, and is the core of agricultural informatization. Digital Agriculture is also called informational agriculture or intelligent agriculture, which refers to the utilization of Digital Earth 
technology, including multi-resolution remote sensing, telemetering, GPS and GIS, computer etc. It also involves all the hi-tech systems which are unified with the agricultural production activity and the production management, such as including rapid collection of farm data on cultivation, land management, agricultural chemicals utilization, contamination control, agricultural engineering equipments and their industrialization technology and so on. It's in short, it's a comprehensive agricultural production management technical system which integrates Digital Earth technology and the modern agricultural technology.

Beginning in the late 90's, Digital Agriculture and the research associated with it was systematically put into practice in developed countries. Now, the research of Digital Agriculture has reached a higher level in those countries. The using of these hi-techs has gotten to a practicable level at many developed countries. They have generally realized that users have been able to collect, manage, product and transmit any kinds of information of agriculture supported by GIS, RS, GPS , DSS and computer network etc..For example, the United States has created an information managing system of crop strains throughout the nation, and allowing the information of more than 600000 sample plants has to be managed by computers. The Plant Protection Bureau of the French Ministry of Agriculture has built nation-wide computer networks to survey and forecast diseases and insects, which can provide the true picture of diseases and insects, the forecast of chemicals and the evaluation of chemical remains. The Japanese Province of Agriculture, Forestry and Aquatic Products has built a data bank system of many crop strains, such as rice, soybeans and wheat, etc. The Research Academy of New Zealand Agriculture and Husbandry provide all sorts of information services, the so-called "farm system"[1].

China is a great agricultural country with a large population, limited soil resources and traditional manual farming methods, with these challenges facing them, the central government has been attaching great importance to the development of agriculture and put forward a new agricultural technology revolution -- the transformation from traditional agriculture to modern agriculture and from extensive farming to intensive farming. From 1998, China officially initiated the concept of "Digital China", and this bring about the encouraging development of Digital Agriculture which can promote agriculture technology revolution, two transformations of agriculture and agricultural development[2]. To-date many provinces have built different kinds of system about Digital Agriculture including an Expert system of wheat, crop simulation modeling, Pesticide Ranking, web-based seedling production Management and so on.

\section{Research Contents of Digital Agriculture}

Digital agriculture is an advanced combination of agricultural science, modern computer technology, network communication and spatial information technology, and the combination will become agricultural development's new pattern in the 21 st century[3].The essence of Digital agriculture is to utilize the digitization of each kind of process in every aspect of agriculture (including crop production, animal husbandry, aquatic products industry, forestry)by using Information Technology. It includes Digital Informationization of Agricultural factors (biological, environmental, technical and social), Digital Informationization of agricultural process, Digital Informationization of agricultural managements (agricultural administration, agricultural production 
management, agricultural science and technology management and agricultural enterprise management). In other words, each agricultural field and process must be expressed by the binary numeral $(0,1)$ and digital model. So Digital Agriculture, with the exception of production of crop, also will include precision gardening, precision foster, precision processing, precision running and management even includes forestry, animal husbandry, foster, processing, production, supply and sale. It is an agriculture technology system with the whole procedure of the whole agriculture will be characterized by digital, network, and intelligence, using technology of remote sensing, telemetry, tele-control, and computer. This will result in effective business, with intelligence management, reasonable job labor for agriculture product - make every square meter have optimized utilization. It will constitutes an information agriculture technology system including monitor and estimating of crop, land, and soil, current or dynamics analyses of crop growth, and factors of environment, diagnose forecast, cultivation step, management planning and decision support[4]

\section{System Architecture of Digital Agriculture}

The system of Digital Agriculture involves various aspects. This includes the construction of a database, Metadata standard, monitoring system, forecasting and

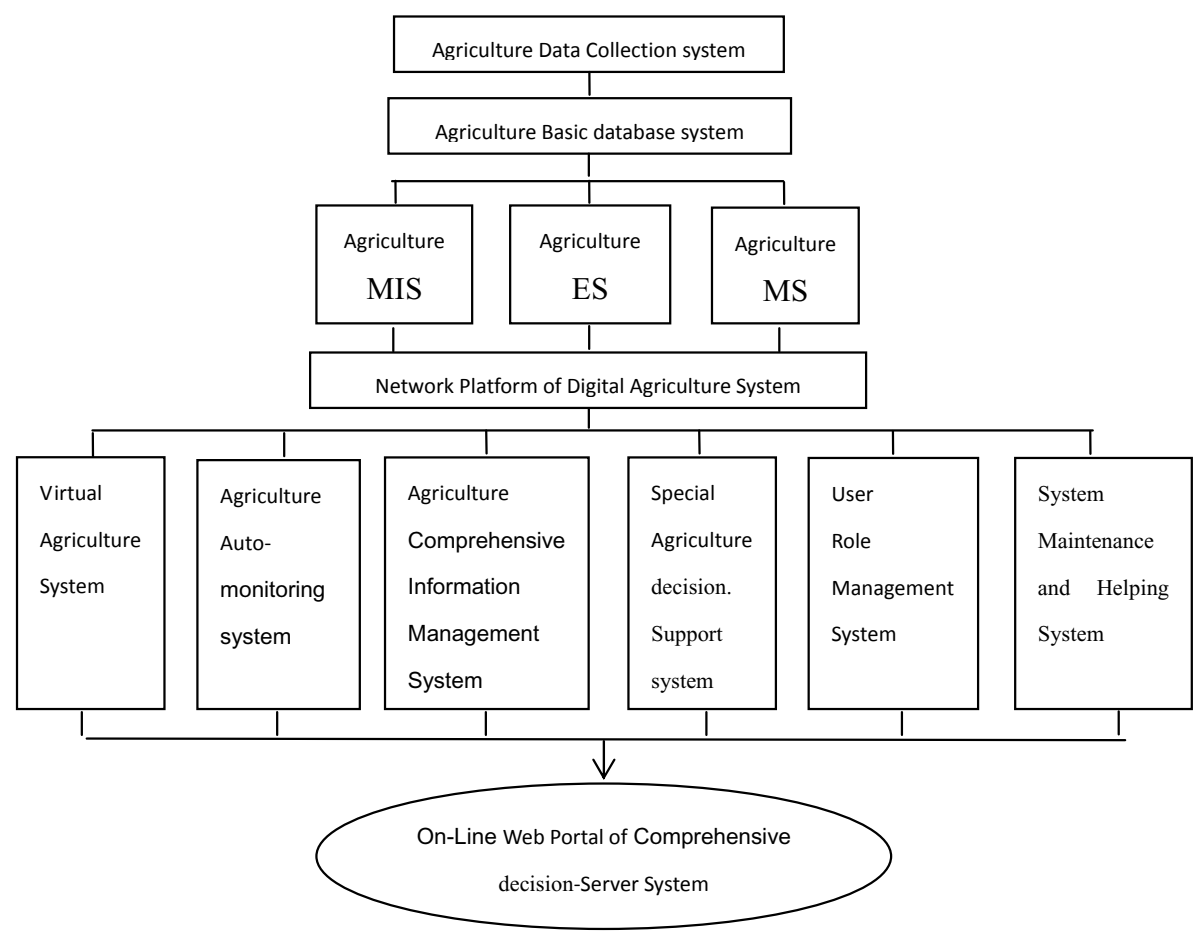

Fig. 1. System Architecture of Digital Agriculture 
decision-making system, and information-releasing system etc. This roughly falls into four levels: information basis level, functional modules level, integral application level and integral web portal level which integrate with each other (Fig.1).

\section{Structural Designing of Digital Agriculture System}

\subsection{Information Basis Level}

The environment of farmland is a very complicated ecology system and involves many different kinds of factors, such as soil, fertilizer, moisture, sunshine, temperature, atmosphere, etc. All of these data includes features of enormous, dynamic, regional, and sequential. In addition, the collection and expression of agricultural data includes not only directly related factors, but also indirectly related factors. So consequentially the information basis level which takes charge of data collection, processing, and analysis is an important and necessary level of Digital Agriculture System.

This level includes public information basis, attribute information basis and spatial data basis facilities. The public information basis includes laws, rules, regulations and technology standards. The attribute information basis takes charge of the management of non-spatial attribute data. The spatial data basis is a consistent, integral geo-spatial data and service system, including spatial data structure of digital agriculture, coordinated management of spatial data, renewing and distribution system, exchange standard of spatial data and metadata, etc.(Fig.2).

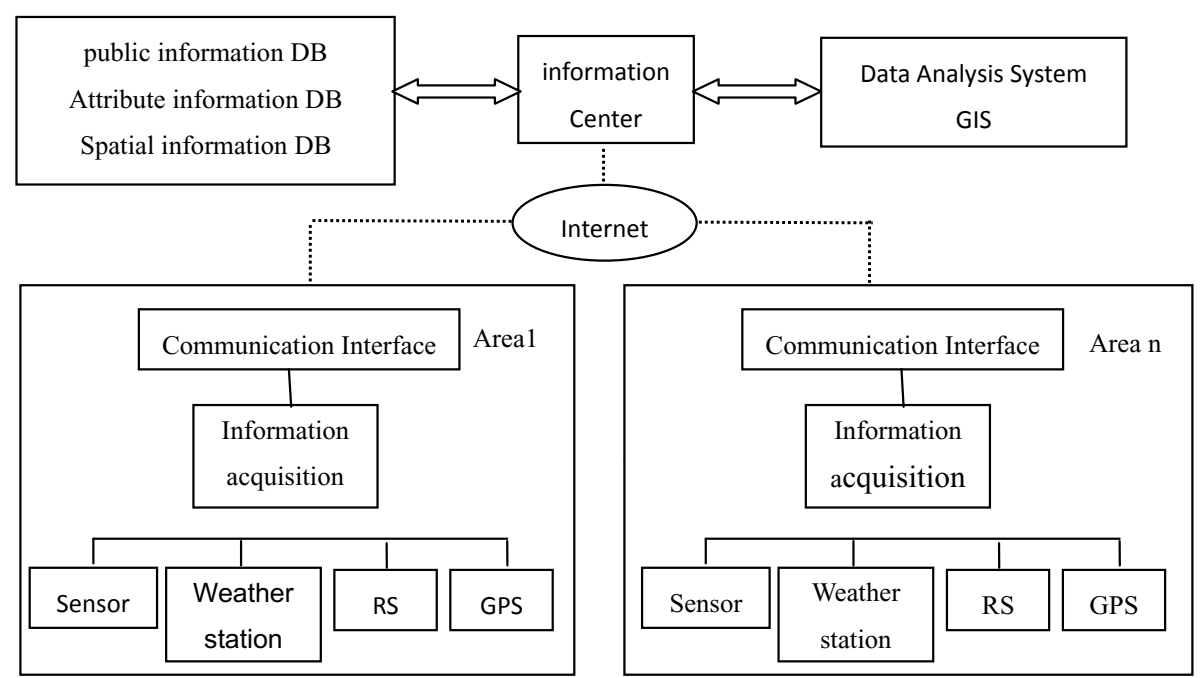

Fig. 2. Information Basis Level

In this level, the acquisition of data includes how to acquire field data rapidly and effectively and how to transmit the field data correctly and at a low cost. Agricultural production environment and agricultural production process includes dispersed 
collection points, long average collection period, low speed, small amount of data, bad conditions of field etc[5]. All of these factors increase the degree of difficulty of data acquisition. This years, the related method and technology of data acquisition includes manual measurement, statistics and analysis of experiments and modern automatic collection. In these methods, modern automatic collection has the features of higher precision, faster speed, wider range of data and more data. This has gradually become the main method of data collection. It involves RS (Remote Sense), GIS (Geography Information System), GPS (Global Position System) and network technology.

\subsection{Functional Modules Level}

Functional Modules Level consists of management, update, search and analysis of agricultural basis information database (non-spatial data and spatial, static and dynamic data), expert knowledge database and agricultural model database. It includes Agriculture MIS (Management Information System), Agriculture ES (Expert System) and Agriculture MS (Model System) (Fig.3).

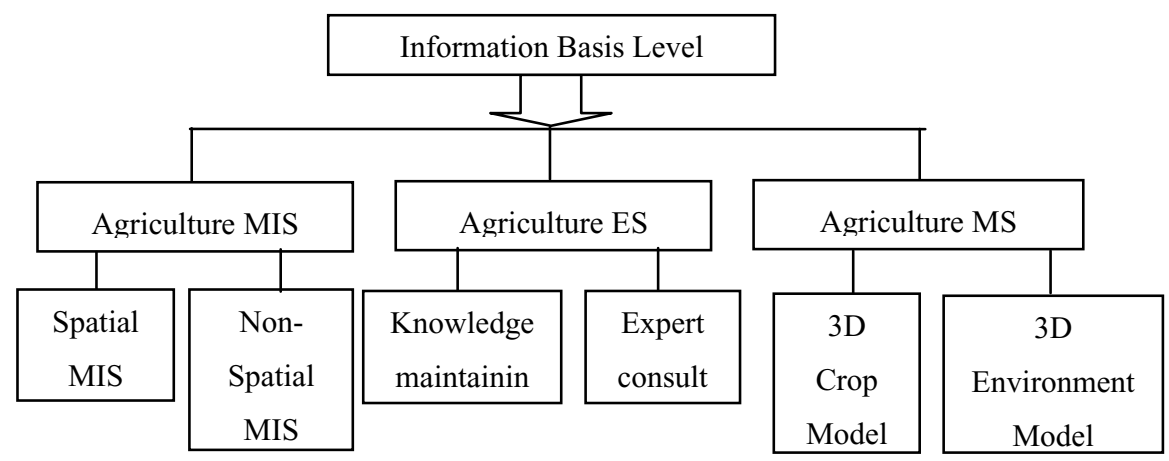

Fig. 3. Functional Modules Level

The function of Agriculture MIS involves the management, update, search, statistic and output of agriculture basic attribute information (such as product, biology, Science and Technology, economy data etc.), and spatial geography information (such as environment resource, agricultural condition, agriculture produce data etc.), it also includes the function of comprehensive management, search, analysis and output of attribute data and spatial data.

Agriculture ES mainly involves the creation of knowledge database, advisory of expert, search and output of knowledge, etc. Knowledge database mainly stores and manages special agriculture expert knowledge; this knowledge includes basic fact (test specimen) of agriculture, book information, common sense, and knowledge from agriculture experts. The quantity and quality of knowledge is the key factor of Expert System and would affect the reliability of the solution.

Agriculture MS is used to store and manage different kinds of agricultural models, such as agricultural spatial analysis models, crop simulation models, comprehensive evaluation models, statistics and analysis models. It is the theory basis for Digital 
Agriculture, process management, intelligent decision of the scientific plan of agriculture production.

\subsection{Integral Application Level}

The integral application level is based on the network platform and takes charge of system integration of different special modules of digital system. It mainly includes agriculture comprehensive MIS, virtual agriculture system, Agriculture DSS (Decision Support System), Agriculture Automatic Monitor System.

\subsubsection{Virtual Agriculture System}

The virtual agriculture is one of the greatest key subsystems of digital agriculture. The rationale of virtual agriculture is the truth that the relationship between crops and environment is computable [6]. The virtual agriculture system takes networks and computers as a platform to simulate and duplicate the studied objects of each link in the agriculture and achieve the aims of interaction and visualization of studied objects and environments. In a broad sense, virtual agriculture includes: virtual crops (Fig.4), virtual animals, virtual agricultural machinery manufacture, virtual farm, etc. [7].

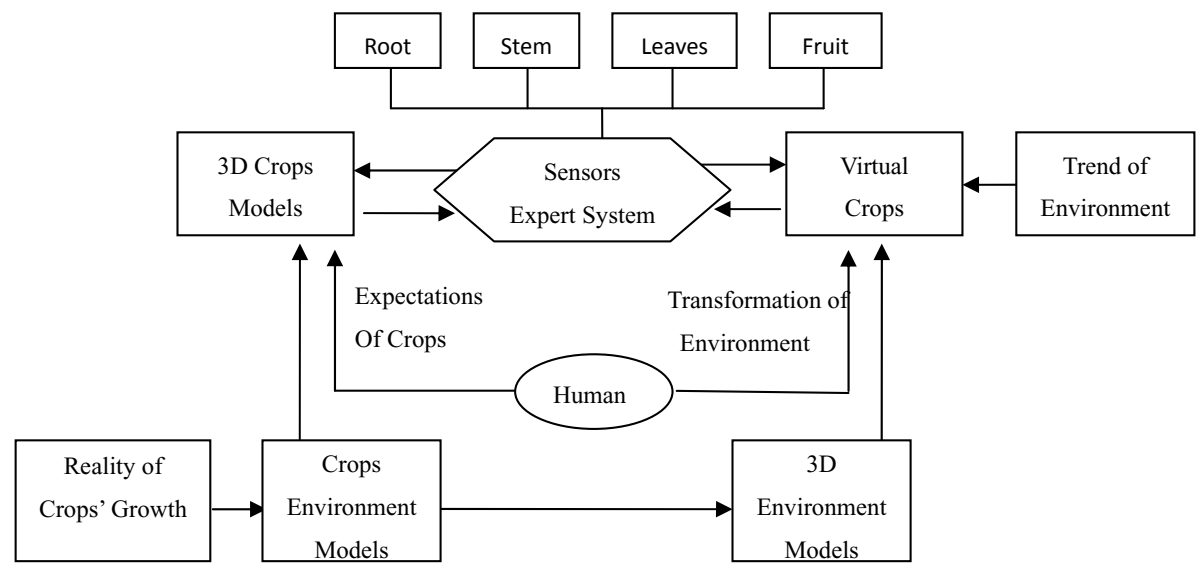

Fig. 4. Architecture of Virtual Crops System

\subsubsection{Agriculture DSS}

Agriculture DSS (Decision Support System) means the use of DSS in the field of agriculture. DSS can be considered as a computer based system which allows the user to solve semi-structural processes by using comprehensive datasets and analytical models, according to El-Najdawi and Stylianou [8]. Agriculture DSS is built on the basis of agriculture information system, crop simulation system and agriculture expert system, and can be used in any fields of agriculture. Today, the research of agriculture DSS has developed from single field decision (such as DSS for Pest Management, cotton efficient fertilization DSS) to an integrative DSS, moving from a single user system to 


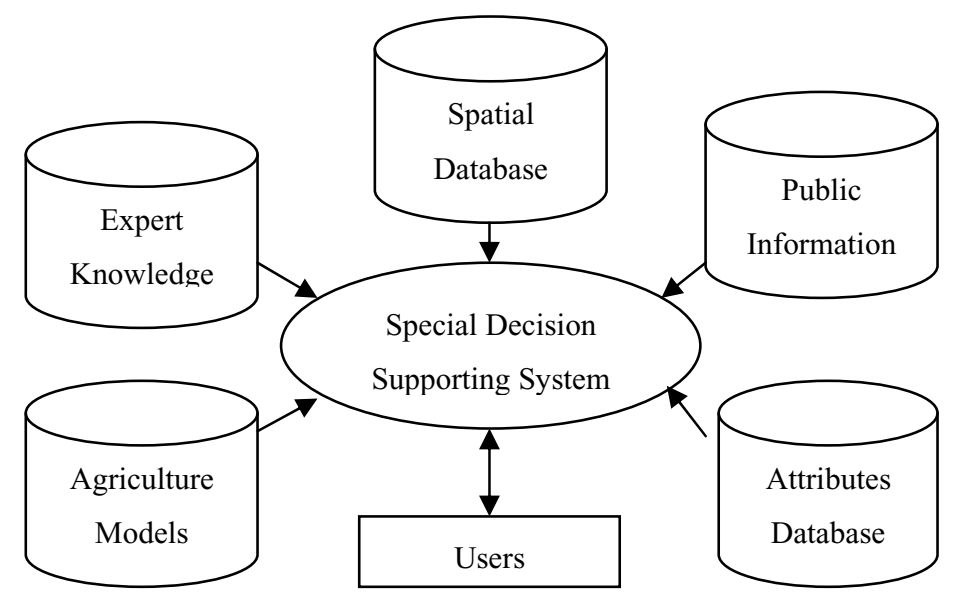

Fig. 5. Agriculture Decision Supporting System

multi-user B/S system. Through Internet, expert knowledge can be obtained at any time, from any place, by any person (Fig. 5).

\subsubsection{Remote Auto-Monitoring System of Agriculture}

Remote Auto-Monitoring System of Agriculture involves the communications between the computer and remote data collectors with the network (such as GSM). The entire system is composed of data management center and remote monitor terminal (Fig.6).

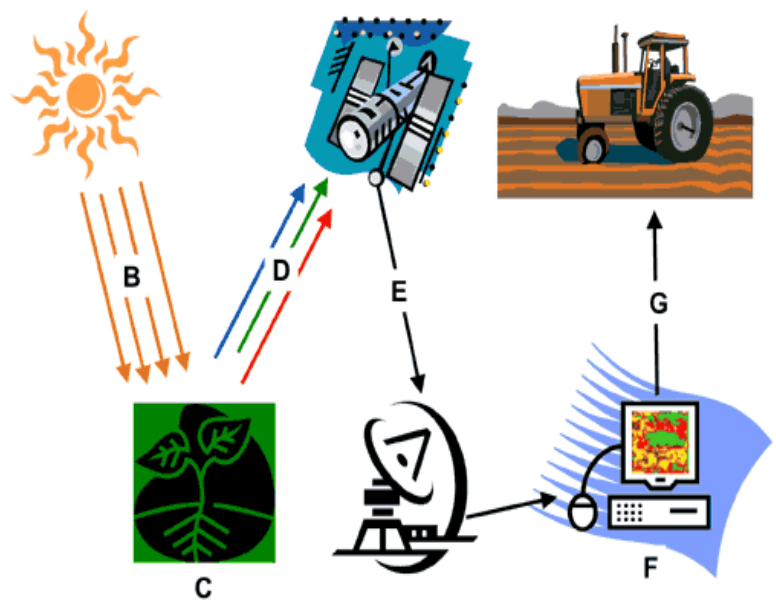

Fig. 6. Remote Monitoring System of Agriculture

The function of the data management center is to control the network module to send and receive messages and to display, store and print the data received from the remote terminal. The function of remote monitor terminal is to send and receive the messages, 
deal with the collected data and send data back to data management center. The system is based on $\mathrm{B} / \mathrm{S}$ mode; users can browse the data and set the parameters using the browser.

\subsection{Comprehensive Integral Web Portal Level}

The Internet is the important technological platform which ensures remote data collection, remote management, remote monitoring of agricultural production. By using the portal website, Digital Agriculture system can integrate collection of data; analysis of data; simulation of process and support decision together and create an integrative flow of information. Users can have different operations and get different results according to their requirement with the browser (Fig.7).

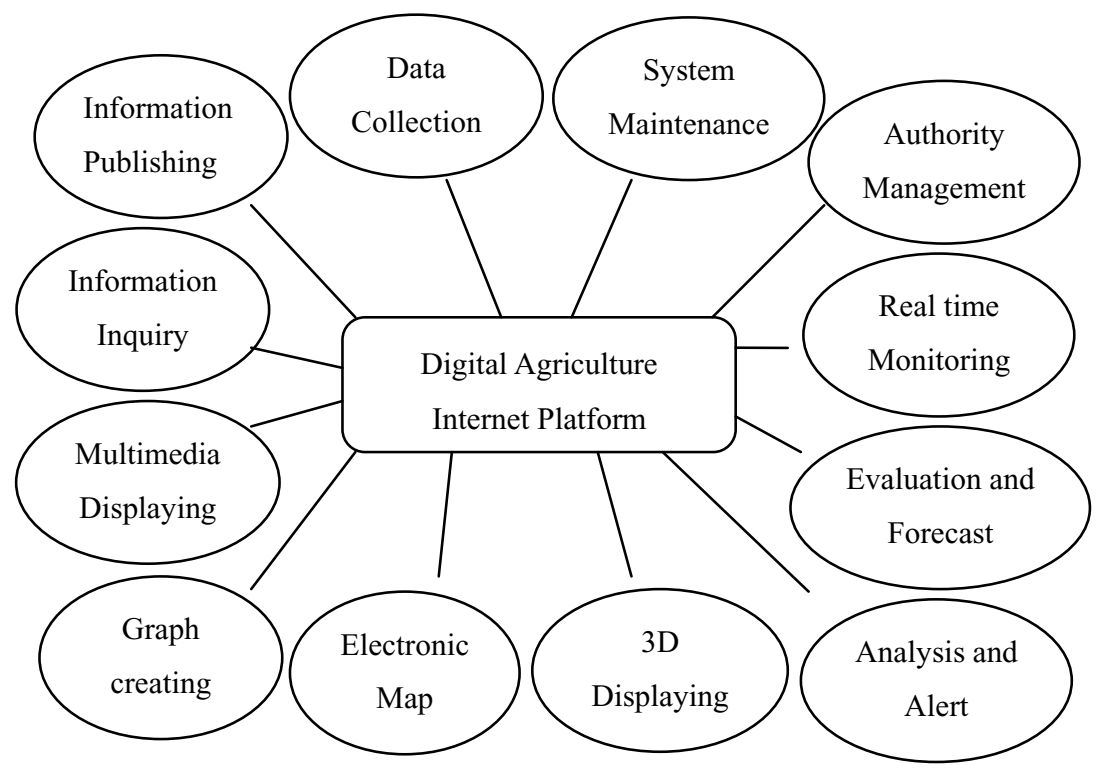

Fig. 7. Internet Server Platform of Digital Agriculture

\section{Summary}

Digital agriculture is based on the modern theory of agriculture while using the technology of digital Earth. It will promote production and maintain developing agriculture by realizing intelligence of procedure of agriculture. The research of Digital Agriculture not only is the support technology but also is the strategic target which modern agriculture will choose inevitably. Implementing Digital Agriculture in different areas in our country is at the exploration stage. In the last ten years, the rationale and application of engineering research system related to the technical system of digital agriculture has become an active domain of high \& new technology research in the developed country. The application and development of digital agriculture in China will become important for agricultural development in the 21 st century. By the 
multi-disciplinary fusions and the coordination, digital agriculture will effectively change the rural industrial structure, increase yield and farmer's income, improve the countryside ecological environment, and realize the sustainable development of agriculture and rural economy.

\section{Acknowledgement}

This work is elaborated within the project of "Research on Growth Evaluation and Physiological-Ecological Simulation of Peach", No. KM201010020011 funded by the Beijing Municipal Commission of Education.

\section{References}

[1] Ouyang, X., Zhang, J.: Some thoughts on the transformation of agricultural information. Review of China Agricultural Science and Technology 4(3), 76-80 (2001)

[2] Liang, Y., Lu, X., Zhang, D.-g., Liang, F., Ren, Z.-b.: Study on the Framework System of Digital Agriculture. Chinese Geographical Science 1(13), 15-19 (2003)

[3] Wei, T., Liu, Y.: Study on the Development Strategy of Digital Agriculture in Hebei Province. Journal of Anhui Agricultural Science 36(30), 13458-13460 (2008)

[4] Cheng, J., Yi, S.: Digital Agriculture-One of Application Domain of Digital Earth. In: Towards Digital Earth - Proceedings of the International Symposium on Digital Earth. Science Press, Beijing (1999)

[5] Sun, G., Zheng, W., Zhao, T., Shen, C.: Study on the Field Soil Moisture Montoring Sytem based on GSM-SMS Technology. In: Proceedings of the 4th International Symposium on Intelligent Information Technology in Agriculture (ISIITA). China Agriculture Science \& Technology Press (2007)

[6] Wang, Y.: Situation and Development of Digital Agriculture. Transactions of the CSAE (suppl.), 9-10 (2003) (in Chinese)

[7] Li, H.: Analysis of Virtual Reality Technology Applications in Agriculture. In: Proceedings of First IFIP TC 12 International Conferences on Computer and Computing Technologies in Agriculture (CCTA 2007), vol. (I), pp. 133-139 (2007)

[8] Liang, Y., Lu, X., Zhang, D., Liang, F.: The Main Content, Technical Support and Enforcement Strategy of Digital Agriculture. Geo-spatial Information Science (Quarterly) 5(1), 68-73 (2002) 